\title{
A cause and effect two-stage BSC-DEA method for measuring the relative efficiency of organizations
}

\author{
Seyed Esmaeel Najafi ${ }^{a}$, Seyed Aliakbar Ahmadi ${ }^{b}$, Mohammad Fallah ${ }^{c}$, Nasser Shahsavaripour ${ }^{d}$ \\ ${ }^{a}$ Department of Industrial Engineering, Science \& Research Branch, Islamic Azad University, Tehran, Iran \\ ${ }^{b}$ Department of Industrial Engineering, Payame Noor University,Tehran, Iran \\ ${ }^{c}$ Department of Industrial Engineering, South Branch, Islamic Azad University, Tehran, Iran \\ ${ }^{d}$ Department of Industrial Engineering, Kerman Branch, Islamic Azad University, Kerman, Iran

A R T I C LEI N F O AB S TRACT \\ Article history: \\ Received 30 June 2010 \\ Received in revised form \\ 10 October 2010 \\ Accepted 12 October 2010 \\ Available online \\ 12 October 2010 \\ Keywords: \\ BSC-DEA

\begin{abstract}
This paper presents an integration of balanced score card (BSE) with two-stage data envelopment analysis (DEA). The proposed model of this paper uses different financial and non-financial perspectives to evaluate the performance of decision making units in different BSC stages. At each stage, a two-stage DEA method is implemented to measure the relative efficiency of decision making units and the results are monitored using the cause and effect relationships. An empirical study for a banking sector is also performed using the method developed in this paper and the results are briefly analyzed.
\end{abstract}

efficiency

cause and effect

balanced score card

data envelopment analysis

\section{Introduction}

During the past few decades, there have been tremendous changes on traditional performance measurement (Charnes et al., 1978; Charnes et al., 1994). The new methods for measuring the performance of different organizations mainly focus on non-financial figures. Kaplan and Norton (1992) are believed to be the first who introduced the idea of balanced score card (BSC). Since then, the idea of BSC has been widely used in different fields of sciences. Kaplan and Norton (1996) explained that the financial reports such as balance sheet or statement do not necessarily represent the critical success factors for an organization. Abran and Buglione (2003) incorporated BSC with QEST model in technology sector. Davis and Albright (2004) performed a comprehensive study on the relationship between the BSC factors and key financial figures. Kaplan and Norton (2004) explained different techniques on changing intangible assets into value-added wealth. BSC is a method to study the competency and the weakness of an organization through a systematic approach which rely on five different perspectives of financial outlook, process, customers, learning and human resources. * Corresponding author. Tel: +989124252899 E-mail addresses: najafi1414@yahoo.com (E. Najafi), 
When a BSC is properly designed we can build a cause and effect relationship between the financial data and other important factors through the implementation of DEA method.

Since the introduction of DEA by Charnes et al. (1978) many have attempted to develop this technique under different conditions. There are literally different types of DEA methods such as constant return to scale, variable return to scale, etc (Charles et al., 1994) but all them use a basic framework where similar units are compared using some input and output factors. The idea of measuring relative efficiency considers a special weight for each input and output and the resulted model can be formulated as an extension of a linear programming problem. DEA methods are traditionally used for non-for-profit organizations where similar units are operating with different input/output and there is basically no revenue. Governmental agencies such as schools, hospitals, public libraries are examples of these cases. However, the implementation of DEA has been expanded for revenue based organizations where financial results are just part of performance measurement (Staub, 2010).

Haslem et al. (1999) for instance used DEA methods for measuring the performance of US banks. Mercan et al. (2003) measured the relative efficiency of Turkish banks with an adaptation of DEA methods. Lin et al. (2009) studied the efficiency of some banks in Taiwan using DEA approaches. One of the primary concerns on the implementation of DEA methods is the absence of a legitimate reason for justifying the weakness on inefficient units. In other words, we may determine the inefficient units using DEA methods but we are not able to find out the actual reasons on why the units are inefficient. One way to resolve this problem is to combine the idea of DEA with BSC approach. The idea of using BSC-DEA has recently become popular among many people. Chen et al. (2008) used this combined methodology for performance measurement of bank industries.

This paper is organized as follows. We first briefly introduce the concept of balanced score card in section 2. Section 3 is devoted to the details of two-stage DEA method. The implementation of an integrated BSC-DEA is given in section 4 for a case study of banking industry. Finally, conclusion remarks are given in section 5 to summarize the contribution of the paper.

\section{Balanced Score Card}

BSC can be used with two objectives. First BSC can be used for designing the attributes of performance measurement. Second, it can be used as a tool to assess the success of the performance measurement. In both cases, we need to find the suitable answers for the following four aspects.

- Financial perspective: What goals do shareholders expect from the management team and what should be done to achieve the required goals?

- Customer perspective: What expectations do customers have from the firm and how should we reach them?

- Internal process: How could we detect and control the key internal processes to reach customer and shareholders satisfaction?

- Learning perspective: How could we learn more about the processes and the market requirements? How do we have to improve the performance through increasing human resource capabilities as well as improving the level of technology?

Kaplan and Norton realized that there is a cause and effect between the goals and the perspectives and we need to have creative people who could continuously learn and improve the performance of an organization by providing innovative plans. Fig. 1 shows the cause and effect relationships among four perspectives. 


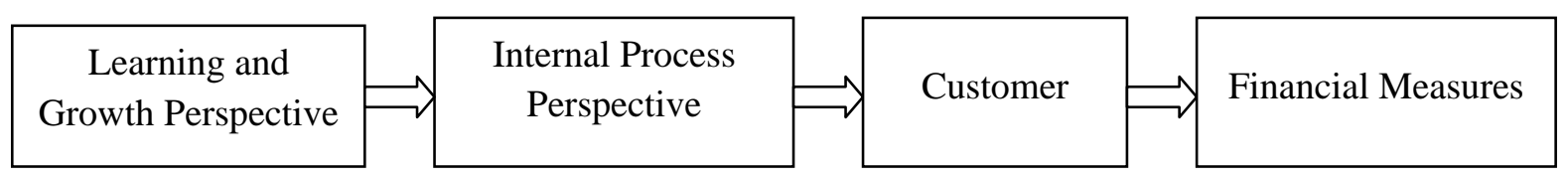

Fig. 1. The cause and effect relationship

When the framework of BSC is implemented properly it will be an easy task to create more value on the system.

\section{Two-stage DEA}

Consider a decision making unit ( $D M U_{j}, j=1, \cdots, n$ ) with $m$ inputs and $s$ outputs and let $y_{r j}$ and $x_{i j}$ be the output and the input of unit $r$ with $r=1, \cdots, s$ and $i=1, \cdots, m$, respectively. Let $u=\left(u_{1}, \cdots, u_{s}\right)$ and $v=\left(v_{1}, \cdots, v_{m}\right)$ be the weights of the output and the input, respectively. Therefore an input oriented DEA can be written as follows,

$\max \quad E=\sum_{r=1}^{s} u_{r} y_{r p}$

subject to

$\sum_{r=1}^{s} u_{r} y_{r j}-\sum_{i=1}^{m} v_{i} x_{i j} \leq 0, \quad j=1, \cdots, n$

$\sum_{i=1}^{m} v_{i} x_{i p}=1$

$v_{i} \geq \varepsilon, \quad i=1, \cdots, n$

$u_{r} \geq \varepsilon . \quad r=1, \cdots, s$

Now an intermediate unit $z_{p j}, p=1, \cdots, q$ according to Fig. 2 can be depicted as follows,

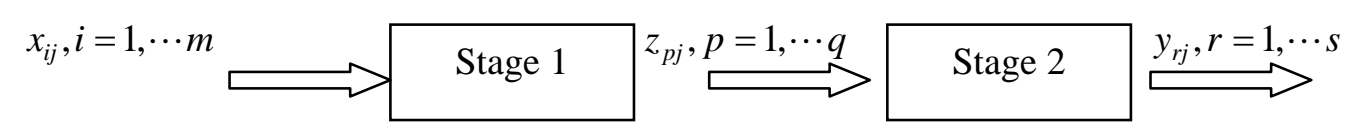

Fig. 2. A two-stage DEA

Let $E_{k}^{1}$ and $E_{k}^{2}$ be the relative efficiencies of stage 1 and 2 , respectively. Then we have $E_{k}=E_{k}^{1} \times E_{k}^{2}$ and the new DEA model can be written as follows (Charles et al., 1996),

$E_{k}^{1}=\max \sum_{p=1}^{q} w_{p} Z_{p k}$

subject to

$\sum_{i=1}^{m} v_{i} X_{i k}=1$,

$\sum_{r=1}^{s} u_{r} Y_{r k}-E_{s} \sum_{i=1}^{m} v_{i} X_{i k}=0$,

$\sum_{r=1}^{s} u_{r} Y_{r j}-\sum_{i=1}^{m} v_{i} X_{i j} \leq 0, \quad j=1, \ldots ., n$,

$\sum_{p=1}^{q} w_{p} Z_{p j}-\sum_{i=1}^{m} v_{i} X_{i j} \leq 0, \quad j=1, \ldots . ., n$,

$\sum_{r=1}^{s} u_{r} Y_{r j}-\sum_{p=1}^{q} w_{p} Z_{p j} \leq 0, \quad j=1, \ldots ., n$,

$u_{r}, v_{i}, w_{p} \geq \varepsilon, \quad r=1, \cdots, s ; i=1, \cdots, m ; \quad p=1, \cdots, q$. 
The dual of model (2) can be written as follows,

$E_{k}=\min a-\left(\sum_{i=1}^{m} s_{l}^{n}+\sum_{p=1}^{q} s_{p}^{w}+\sum_{w=1}^{s} s_{i}^{n}\right)$

subject to

$a x_{a}-\sum_{l=1}^{s} a_{j} X_{q}-\sum_{p=1}^{s} \beta_{t} x_{y}-s=0, \quad i=1, \ldots ., m$,

$\sum_{j=1}^{n} \beta_{l} Z_{p l}-\sum_{j=1}^{a} \gamma_{l} Z_{p l}-s_{p}^{w}=0, \quad p=1, \ldots ., q$,

$\sum_{j=1}^{m} \alpha_{l} Y_{r j}+\sum_{j=1}^{s} \gamma_{l} Y_{r j}-s_{p}^{w}=Y_{r k}, \quad r=1, \ldots ., s$,

$\alpha_{j}, \beta_{l}, s_{l}^{w}, s_{p}^{w}, s_{r}^{w} \geq 0, \quad j=1, \ldots ., n ; r=1, \ldots ., s ; i=1, \ldots ., m ; \quad p=1, \ldots, q$.

DEA model (2) and (3) can be used to measure the relative efficiency of different units. However we need to be cautious on using the models for two reasons. First, the model is designed for constant return to scale and second, the relative importance for the output of the first stage is the same as the input of the second stage. There are alternative methods that could be used whenever the return to scale would not be constant. Interested reader could see Kao and Hwang (1994) for more details.

\section{The proposed cause and effect two-stage BSC-DEA method}

In this section, we propose a two-stage DEA method which incorporates the advantage of both BSC and DEA methods. The proposed method of this paper is applied for a case study of private bank in Iran. The proposed cause and effect BSC-DEA first determines the necessary input/output for learning perspective of BSC-DEA and using model (2) determines the relative efficiency of different DMUs. Next, the model uses the outputs of the learning perspective as an input for the internal process and a two-stage BSC-DEA is implemented in this stage. Again, we determine the important input/output factors for customer perspective and run the two-stage BSC-DEA and finally we use financial figures to conclude our performance measurement. We use the information of six Iranian banks to perform the details of the implementation of our proposed model.

As we have already explained, the BSC consists of four different stages. For the learning perspective in stage one, Incentive fees and an increased staff expertise are considered as input DEA parameters. Also the increase employee skills and speed service are considered as the output of the DEA approach. Table 1 summarizes the information of these four DEA input/output for the learning perspective.

Table 1

DEA input/output for learning perspective

\begin{tabular}{lcccc}
\hline \multirow{2}{*}{ DMU } & \multicolumn{2}{c}{ Input } & \multicolumn{2}{c}{ Output } \\
\cline { 2 - 5 } & Incentive fees(\%) & increased staff expertise & increase employee skills & speed service \\
\hline 1 & 23.03 & 12.11 & 54.58 & 800 \\
2 & 18.72 & 11.96 & 30.80 & 692 \\
3 & 18.50 & 12.08 & 46.25 & 718 \\
4 & 5.30 & 12.07 & 18.55 & 18.55 \\
5 & 17 & 11.96 & 39.10 & 39.10 \\
6 & 3 & 13.66 & 69 & 69 \\
\hline
\end{tabular}

In the second stage of BSC, internal process perspective, advanced and high speed services are considered as two important inputs. Online services and competitive pricing are also used as the 
necessary outputs. Table 2 summarizes the results of the information of input/output for the second stage.

Table 2

DEA input/output for internal process perspective

\begin{tabular}{lcccc}
\hline \multirow{2}{*}{ MMU } & \multicolumn{2}{c}{ Input } & \multicolumn{2}{c}{ Output } \\
\cline { 2 - 5 } & Advanced Services & High speed Services(\%) & Online service & Competitive pricing(\%) \\
\hline 1 & 91 & 3.13 & 1376 & 15.7 \\
2 & 57 & 3.41 & 1896 & 18.9 \\
3 & 8 & 3.25 & 1842 & 34 \\
4 & 37 & 3.32 & 1315 & 33.5 \\
5 & 34 & 3.25 & 787 & 30.4 \\
6 & 10 & 3.35 & 510 & 12 \\
\hline
\end{tabular}

Note that the outputs of the internal perspective are used as input of customer perspective. The output parameters for the third stage, customer perspective, are summarized as follows,

Table 3

DEA output for customer perspective

\begin{tabular}{|c|c|c|c|}
\hline \multirow[t]{2}{*}{ DMU } & \multicolumn{3}{|c|}{ Outputs in terms of percentage } \\
\hline & Customer satisfaction & Customer attraction rate & High quality service \\
\hline 1 & 3.25 & 22.91 & 3.19 \\
\hline 2 & 3.21 & 25.8 & 3.61 \\
\hline 3 & 3.41 & 29.0 & 3.34 \\
\hline 4 & 3.12 & 34.50 & 3.41 \\
\hline 5 & 3.43 & 21.8 & 3.93 \\
\hline 6 & 3.74 & 13 & 3.5 \\
\hline
\end{tabular}

Again, the outputs of customer perspective are used as input for financial perspective. We have considered return on equity, profit margin and growth of asset value as outputs for the fourth stage. Table 4 shows the output information of this stage.

Table 4

DEA output for customer perspective

\begin{tabular}{lccc}
\hline \multirow{2}{*}{ DMU } & \multicolumn{2}{l}{ Outputs in terms of percentage } & Growth of asset value \\
\cline { 2 - 4 } & Return on equity & Profit margin & 4.81 \\
1 & 1.48 & 17.42 & 7.16 \\
2 & 2.62 & 12.98 & 7.00 \\
3 & 8.00 & 47.59 & 1.4 \\
4 & 2.7 & 18.9 & 1.23 \\
5 & 3.0 & 20.13 & 1.02 \\
6 & 4.0 & 10.28 & \\
\hline
\end{tabular}

Now we can study the cause and effect relationships between each section of BSC stage by solving DEA model (2) and discuss the details of the results in order to find the possible weakness on the system. Table 5 demonstrates the details of our DEA implementation between the first two stages of learning and growth and internal process perspectives. As we can observe from Table 5, unit 1 and unit 4 are located on efficient frontier and it seems that there is a logical cause and effect between these two units. Units of 2, 3, 5 and 6 are not efficient which means there are some problems with these units. 
Table 5

DEA results for the first and the second stages

\begin{tabular}{lcccccc}
\hline Evaluation unit & DMU1 & DMU2 & DMU3 & DMU4 & DMU5 & DMU6 \\
\hline $\begin{array}{l}\text { Efficiency between learning and growth and } \\
\text { internal perspectives }\end{array}$ & 1 & 0.961 & 0.9425 & 1 & 0.8552 & 0.6842 \\
Efficiency of learning and growth & 1 & 1 & 1 & 1 & 0.952 & 0.725 \\
Efficiency of internal process & 1 & 0.961 & 0.9425 & 1 & 0.893 & 0.939 \\
\hline
\end{tabular}

Units 2 and 3 are efficient in terms of learning and growth but there are some weaknesses on their internal process. Units 5 and 6 have difficulties in both learning and internal process and we need to do more investigation on improving these two perspectives for them. Another interesting survey is to look for the efficiencies of six units between internal processes and customer perspectives. Table 6 summarizes the details of the DEA implementation.

Table 6

DEA results for the second and the third stages

\begin{tabular}{lcccccc}
\hline Evaluation unit & DMU1 & DMU2 & DMU3 & DMU4 & DMU5 & DMU6 \\
\hline $\begin{array}{l}\text { Efficiency between internal and customer } \\
\text { perspectives }\end{array}$ & 0.737 & 0.922 & 0.9252 & 1 & 1 & 1 \\
$\begin{array}{l}\text { Efficiency of internal perspective } \\
\text { Efficiency of customer perspective }\end{array}$ & 0.943 & 0.950 & 0.960 & 1 & 1 & 1 \\
\hline
\end{tabular}

According to Table 6, units 4, 5 and 6 are efficient in terms of two internal and customer perspectives. This confirms that there is a logical cause and effect between these three units. Despite the fact that unit 5 and 6 are determined to be efficient based on the results reported on Table 6, we cannot accept these two units as efficient units since they were not recognized as efficient units in the previous parts and we need to do more investigation on these two units. Units 1, 2 and 3 have some problems in both internal and customer perspectives. Next step is to measure the relative efficiencies of six units based on customer and financial perspectives. Table 7 summarizes the results of our survey.

\section{Table 7}

DEA results for the third and the last stages

\begin{tabular}{lcccccc}
\hline Evaluation unit & DMU1 & DMU2 & DMU3 & DMU4 & DMU5 & DMU6 \\
\hline $\begin{array}{l}\text { Efficiency between customer and financial } \\
\text { perspectives }\end{array}$ & 0.781 & 1 & 1 & 0.672 & 0.768 & 1 \\
$\begin{array}{l}\text { Efficiency of customer perspective } \\
\text { Efficiency of financial perspective }\end{array}$ & 0.840 & 1 & 1 & 0.97 & 0.842 & 1 \\
\hline
\end{tabular}

According to the results of Table 7, unit 4 and unit 5 perform poorly in terms of financial and customer perspectives. Once we look at the performance of the unit 4 we realize that this unit performs poorly on its financial perspective. Since this unit performs well in terms of the previous perspectives we must focus on its financial reports and try to find the weakness on this part. Table 8 summarizes the efficiency estimation of balanced score card based on four perspectives. As we can see from Table 8 , there is a logical cause and effect relationships among all four perspectives for unit 4. In order to improve the efficiency of unit 2, 3, 5 and 6 we may need to start from the first stage of learning. 
Table 8

DEA results for the third and the last stages

\begin{tabular}{|c|c|c|c|c|c|c|}
\hline Evaluation unit & DMU1 & DMU2 & DMU3 & DMU4 & DMU5 & DMU6 \\
\hline $\begin{array}{l}\text { Efficiency between learning and growth and } \\
\text { internal processes perspectives }\end{array}$ & 1 & 0.961 & 0.9425 & 1 & 0.8552 & 0.6842 \\
\hline $\begin{array}{l}\text { Efficiency between internal process and } \\
\text { customer perspectives }\end{array}$ & 0.737 & 0.922 & 0.9252 & 1 & 0.842 & 1 \\
\hline $\begin{array}{l}\text { Efficiency between customer and financial } \\
\text { perspectives }\end{array}$ & 0.781 & 1 & 1 & 0.672 & 0.768 & 1 \\
\hline
\end{tabular}

The logical cause and effect relationships among different BSC perspectives in this case study could possibly help us find all possible issues in any organization.

\section{Conclusions}

In this paper, we have presented a cause and effect balanced score card method to study the performance of an organization. We have used four stages for our BSC study and a two-stage DEA method was implemented in each stage of BSC investigation. The proposed method of this paper has been implemented for a real-world case study in Iranian banking sector. The preliminary results indicate that we may use this methodology to improve the performance of an organization through a logical cause and effect relationships.

\section{Acknowledgment}

The authors would like to thank the anonymous referees for their constructive comments on earler version of this work.

\section{References}

Abran A., \& Buglione L. (2003). A multidimensional performance model for consolidating Balanced Scorecards, Advances in Engineering Software, 34, 339-349.

Andersen, P., \& Petersen, N. C. (1993). A procedure for ranking efficient units in data envelopment analysis, Management Science, 39, 1261-1264.

Charnes A, Cooper, W. W., Rhodes, E. (1978). Measuring the efficiency of decision making units. European Journal of the Operational Research, 2, 429-44.

Charnes A, Cooper W. W., Lewin, A., Seiford, L. M. (1994). Data envelopment analysis: theory, methodology and applications. Massachusetts: Kluwer Academic Publishers.

Chen T., Chen C., \& Peng S. (2008). Firm operation performance analysis using data envelopment analysis and balanced scorecard .A case study of a credit cooperative bank, International Journal of Productivity and Performance Management, 57, 523-539.

Davis S., \& Albright, T. (2004). An investigation of the effect of Balanced Scorecard implementation on financial performance, Management Accounting Research, 15, 135-153.

Haslem, J. A., Scheraga, C. A., \& Bedingfield, J. P. (1999). DEA efficiency profiles of U.S. banks operating internationally. International Review of Economics \& Finance, 8(2), 165-182.

Kaplan, R.S. \& Norton, D.P. (1992). The balanced scorecard - measures that drive performance, Harvard Business Review, 70(1), 71-79. 
Kaplan, R.S. and Norton, D.P. (1996). The balanced scorecard: translating strategy into action, Harvard Business School Press, Boston, MA.

Kaplan, R.S. \& Norton, D.P. (2004), Strategy maps: converting intangible assets into tangible outcomes, Harvard Business School Press, Boston, MA.

Kao, C., Hwang, S-N., (2008). Efficiency decomposition in two-stage data envelopment analysis: an application to non-life insurance companies in Taiwan. European Journal of Operational Research, 185 (1), 418- 429.

Lin, T. T., Lee, Ch-Ch., \& Chiu, T-F. (2009). Application of DEA in analyzing a bank's operating performance. Expert Systems with Applications, 36(5), 8883-8891.

Mercan, M., Reisman, A., Yolalan, R., \& Burak Emel, A. (2003). The effect of scale and mode of ownership on the financial performance of the Turkish banking sector: results of a DEA-based analysis, Socio-Economic Planning Sciences, 37(3), 185-202.

Staub, R. B., Da Silva e Souza, G. \& Tabak, B. M. (2010). Evolution of bank efficiency in Brazil: A DEA approach. European Journal of Operational Research, 202(1), 204-213. 